\title{
A Implantação do PTS na Organização do Trabalho: uma Estratégia do Cuidado no Contexto Hospitalar
}

\author{
Schmidt, Denise Pasqual; Pfeifer, Paula Moraes; Bick, Miguel Armando; Bressan, \\ Jéssica Viaro; Machado, Andressa Guimarães; Ortiz, Leodi Conceição Meireles
}

Hospital Universitário de Santa Maria —dps@ufsm.br

Introdução: o Projeto Terapêutico Singular (PTS) é uma nova ferramenta que se propõe a ultrapassar as fronteiras existentes entre os diferentes saberes que se ocupam da produção de saúde. É definido como um conjunto de ações com objetivo de cuidar dos pacientes de forma individualizada, por meio da escuta e interação democrática entre equipe, família e paciente. Objetivo: Este trabalho visa apresentar dados preliminares da pesquisa de implantação do PTS em unidade hemato-oncológica de hospital público do interior do estadol. Método: Optou-se pela realização de uma pesquisa-ação, uma abordagem não-convencional que adota seminários como técnica para a coleta de dados. Os sujeitos da pesquisa foram membros da equipe de saúde da hemato-oncologia pediátrica. Os seminários foram realizados entre os participantes e almejaram promover a discussão e a elaboração coletiva de alternativas para uma melhor assistência. Foi utilizado, também, questionário contendo oito perguntas abertas que visavam compreender a percepção do participante a respeito da experiência vivenciada de implantação do projeto. Resultados: a partir do questionário proposto a nove pessoas, uma destas julgou-se incapaz de opinar pela pouca participação nos encontros, apenas uma participou integralmente e outra relatou dificuldades em função do horário de trabalho. a maioria dos participantes nunca havia participado de projetos como este, mas descreveu o PTS como uma experiência interessante, impar, desafiadora e gratificante, que possibilita uma visão integral do paciente e, que por isso, deveria ter continuidade. Porém, destacaram a não adesão dos profissionais como uma dificuldade. um dos participantes acreditava que a justificativa para a ausência de outras áreas nos encontros estava no desconhecimento do projeto e ou necessidade de participar de escalas. Achados preliminares da pesquisa reforçam dados da literatura que apontam como fatores que dificultam a atividade e 0 desenvolvimento de novas técnicas, a organização hospitalar e as características do trabalho. na instituição hospitalar o modelo tradicional altamente hierarquizado de acordo com o saber, divide os homens e as tarefas. Além disso, as condições de trabalho na rede pública de saúde são uma questão delicada: há um aumento no número de pacientes e redução da equipe de profissionais, jornadas de trabalho prolongadas, ritmos acelerados de produção, hierarquia rígida e vertical, fragmentação de tarefas e a desqualificação do trabalho realizado. Conclusão: a prática hospitalar ainda está centrada no desenvolvimento de tarefas, as quais são realizadas de forma isolada, muitas vezes sem articulação e comunicação. a construção de novas práticas, como o PTS é essencial, por possibilitar a aquisição de ferramentas para a melhoria do cuidado prestado ao paciente e, portanto, se deve buscar favorecer a organização do trabalho da equipe se saúde de modo a contemplar tal demanda.

Schmidt, Denise Pasqual; Pfeifer, Paula Moraes; Bick, Miguel Armando; Bressan, Jéssica Viaro; Machado, Andressa Guimarães; Ortiz, Leodi Conceição Meireles. A Implantação do Pts na Organização do Trabalho: uma Estratégia do Cuidado no Contexto Hospitalar. In: Anais do Congresso Internacional de Humanidades \& Humanização em Saúde [= Blucher Medical Proceedings, num.2, vol.1]. São Paulo: Editora Blucher, 2014. ISSN 2357-7282

DOI 10.5151/medpro-cihhs-10473 